\title{
A new species of Litarachna (Acari: Hydrachnidiae: Pontarachnidae) from Sagami Bay, central Japan
}

\author{
Akira Moto ${ }^{1} \&$ Hiroshi Abé \\ ${ }^{\prime}$ Department of Marine Science and Resources, College of Bioresource Sciences, Nihon University, \\ Kameino 1866, Fujisawa, Kanagawa 252-0880, Japan. \\ E-mail: brak10149@g.nihon-u.ac.jp \\ ${ }^{2}$ Biological laboratory, College of Bioresource Sciences, Nihon University, \\ Kameino 1866, Fujisawa, Kanagawa 252-0880, Japan. \\ E-mail: acari@brs.nihon-u.ac.jp
}

\begin{abstract}
A species in the marine water mite family Pontarachnidae is newly described under the name of Litarachna sagamiensis sp. nov. This species is found in intertidal algae in Sagami Bay on the Pacific coast of Japan. The present new species is characterized by the following: (1) The right and left first coxal plates are separated from each other; (2) the ventral tubercles on the second segment of palp is absent; (3) the ventral tubercle on the fourth segment of palp is present; (4) the ventral glandularium is separated from the first ventral platelet; (5) the ventral glandularium and ventral platelet are located posteriorly to the posterolateral apodeme of fourth coxal plate; (6) the posterolateral apodeme is slender; (7) three pairs of wheel-like acetabula are present in the female; and (8) 49 perigenital setae are present in the male. Litarachna sagamiensis sp. nov. resembles $L$. duboscqi, L. hongkongensis, and L. marshalli in general morphology, but the new species differs from the latter three species by the condition of the ventral glandularium, the positions of the ventral glandularium and the first ventral platelet, the number of wheel-like acetabula in the female, the shape of the distal margin of medioposterior apodeme in the male, and the number of perigenital setae in the male. This is the third species in the genus Litarachna described from Japan.
\end{abstract}

Key words - Litarachna, water mites, Pontarachnidae, new species, Japan

\section{Introduction}

The water mite family Pontarachnidae is the only family inhabiting the marine environment in the subcohort Hydrachnidiae. Pontarachnid mites usually live on seaweeds, on stones and rocks, and in sand interstices in an intertidal zone. This family is composed of two genera: Pontarachna Philippi 1840, and Litarachna Walter 1925. The genus Litarachna, including 21 species, lives in littoral zones all over the world (Smit 2002, Pešić et al. 2012), and the following 12 species have been known in the Pacific Ocean: L. amnicola, L. bartschae and L. halei from Australia (Womersley 1937, Cook 1986, Smit 2003, Pešić \& Smit 2009), L. bruneiensis from Brunei (Pešić et al. 2011), L. curtipalpis from Australia and Singapore (Smit 2003, 2009), L. denhami from Australia and South Korea (Lohmann 1909, Pešić et al. 2008, Smit 2003), L. hongkongensis from China (Smit 2002), L. muelleri from Malaysia (Smit 2008), L. sabangensis from the Philippines (Viets 1984), L. triangularis from Singapore (Smit 2009), and $L$. divergens and L. kamui from Japan (Uchida 1935, Honma \& Kitami 1978, Abé 2005). Thus, only two species, $L$. divergens and $L$. kamui, have been so far known to live in Japanese waters. During the meiofaunal survey on the
Pacific coast of central Japan in 2012, we discovered several marine water mites from littoral seaweeds. In the present paper, we describe a new species of the genus Litarachna on the coast of Kanagawa Prefecture, central Japan.

\section{Materials and methods}

Sampling took place on the coast in Zushi City (N 35 $17^{\prime}$ $34^{\prime \prime}$, E $139^{\circ} 33^{\prime} 56^{\prime \prime}$ ) and Yokosuka City (N $35^{\circ} 11^{\prime} 49^{\prime \prime}$, E $139^{\circ} 36^{\prime} 04^{\prime \prime}$ ) in Kanagawa Prefecture, Japan. Sargassum sp. in the intertidal zone less than $0.5 \mathrm{~m}$ depth were taken by hand, and the mites were extracted from these algae by means of decanting and sieving. Mites were picked up by using a needle from the substrate under a binocular stereoscopic microscope. Specimens were fixed with and dissected in modified Imamura's fluid (Imamura 1965), mounted in glycerine jelly, and then sealed with Canada balsam under a binocular stereoscopic microscope. Observation was made under a light microscope. Figures were drawn with the aid of a camera lucida, and measurements were made with an ocular micrometer. All measurements are given in micrometers $(\mu \mathrm{m})$. Meristic characters are sometimes given as ranges.

The body parts were measured in the following format: (1) Idiosoma: length - from the anterior-most margin of 


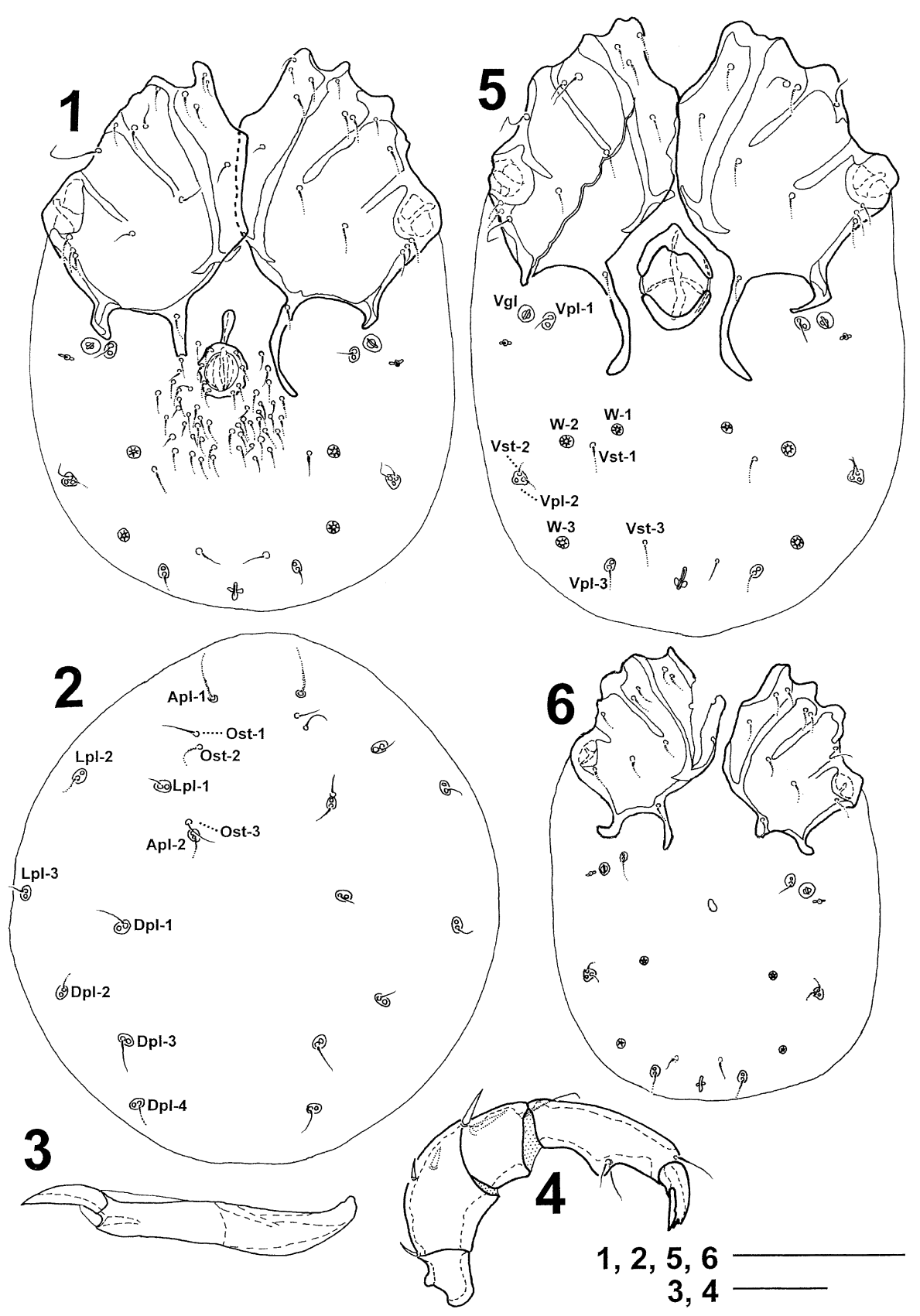

Figs. 1-6. Litarachna sagamiensis sp. nov., male holotype (1-4), female allotype (5) and nymph paratype (6). 1, idiosoma, ventral view; 2, same, dorsal view; 3 , chelicera, lateral view; 4, right palp, lateral view; 5, idiosoma, ventral view; 6 , same, ventral view. Scales $=100$ $\mu \mathrm{m}(1,2,5,6) ; 50 \mu \mathrm{m}(3,4)$.

the first coxal plate to the terminal end of the idiosoma; width — at the widest level. (2) Segments of leg: length - straight dorsal length from the proximal base to the distal end. (3) Segments of palp: length — straight dorsal length from the proximal base to the distal end; height — height at the proximal base and distal end of the segment. (4) Segments of chelicera: length - straight ventral length from the proximal base to the distal end. (5) First to fourth coxal plates: length - from the anterior-most margin of the first coxal plate to the posterior-most margin of the fourth coxal plate along the longitudinal axis; width — at the widest level. (6) Medial and lateral apodemes: length - from the posterior margin of the fourth coxal plate to the distal end of these apodemes (7) Genital field: length - from the anterior margin to the posterior margin along the longitudinal median axis; width - at the widest level. (8) Pre- and postgenital sclerites in the female: width — at the widest level.

Comparative material examined. We examined the type specimen of the following species for the 
morphological comparison: Litarachna hongkongensis, holotype, female, on Serpulidae (Polychaeta), Starfish Bay, Hong Kong, 20 April 1989, leg. I. Bartsch, deposited in the Zoological Museum Amsterdam, Netherlands.

Terminology. Terms on glandularia, platelets, setae and acetabula were referred to Tuzovskij (1987) and Wiles et al. (2002). Right or left is referred on the basis of a dorsal view. The number of paired setae, glandularia, and platelets on the right and left sides of idiosoma is referred only to the one side.

Coxal plate: Four pairs of chitinous plates surrounding right and left coxae on anterior idiosoma. The first to fourth coxal plates on the right and left side of idiosoma are fused into the single large coxal plate on each side.

Posteromedial and posterolateral apodemes: Posteromedial and posterolateral projections on the posterior margin of the fourth coxal plate.

Genital field: An area including the gonopore and the sclerotized plate surrounding the pore.

Sclerotized ring: A sclerotized plate surrounding the gonopore in the male.

Genital sclerites: Two sclerotized plates placed anteriorly (pregenital) and posteriorly (postgenital) to the gonopore in the female.

Genital seta: A seta on the sclerotized ring in male.

Perigenital seta: A seta around the genital field in the male.

Ventral glandularium: A ventral gland located on the distal margin of fourth coxal plate, or the membranous cuticle posteriorly to posterolateral apodeme, or the membranous cuticle between posteromedial and posterolateral apodeme of fourth coxal plate.

Wheel-like acetabulum: A wheel-like structure with radiating sulci placed on the membranous cuticle posteriorly to coxal plates. This term is named by Cook (1996).

Lyrifissure: A fissure placed on the membranous cuticle posteriorly to the posterolateral apodeme.

Platelet: A small plate furnished with a gland and a seta.

Ventral platelet: A platelet placed on the ventral membranous cuticle.

Ventral seta: A seta placed on the membranous cuticle posteriorly to coxal plates.
Ocular seta: A seta placed on the anterodorsal membranous cuticle.

Anterior platelet: A platelet placed on the anterodorsal membranous cuticle.

Lateral platelet: A platelet placed on the lateral membranous cuticle.

Dorsal platelet: A platelet placed on the dorsal membranous cuticle.

Abbreviations.

Cx-I, II, III, IV: First to fourth coxal plates

Leg-I, II, III, IV: First to fourth legs

P-1, 2, 3, 4, 5: First to fifth segments of palpi

PMA: Posteromedial apodeme(s)

PLA: Posterolateral apodeme(s)

W-1, 2, 3, 4: First to fourth wheel-like acetabula ("W1," "W2," "W3," and "W4" sensu Wiles et al. (2002))

Vgl: Ventral glandularium(a) ("gl.c" sensu Tuzovskij (1987); "V3 gland" sensu Wiles et al. (2002))

Vpl-1, 2, 3: First to third ventral platelets ("Pe," "Sce," and "Se" sensu Tuzovskij (1987); "E4," "L3," and "V4" sensu Wiles et al. (2002))

Vst-1, 2, 3: First to third ventral setae ("Pi," "Ce," and "Ci" sensu Tuzovskij (1987); "V1" to "V3" sensu Wiles et al. (2002))

Ost-1, 2, 3: First to third ocular setae ("Fp," "Vi," and "Oi” sensu Tuzovskij (1987); "A1," "R1," and "R2" sensu Wiles et al. (2002))

Apl-1, 2: First and second anterior platelets ("Fch" and "Hi" sensu Tuzovskij (1987); “A1" and "A2" sensu Wiles et al. (2002))

Lpl-1, 2, 3: First to third lateral platelets ("Oe," "Ve," and "Le" sensu Tuzovskij (1987); "L1," "L2," and "L4" sensu Wiles et al. (2002))

Dpl-1, 2, 3, 4: First to fourth dorsal platelets ("He," "Le," "Li," and "Si" sensu Tuzovskij (1987); "D1" to "D4" sensu Wiles et al. (2002))

Table 1. Length of segments of right and left palpi of male (holotype).

\begin{tabular}{cccccc}
\hline Palp & P-1 & P-2 & P-3 & P-4 & P-5 \\
\hline Right & 15 & 65 & 28 & 73 & 28 \\
Left & 15 & 70 & 23 & 78 & 28 \\
\hline
\end{tabular}

Table 2. Chaetotaxy of right and left legs of male (holotype), right/left; S: spiniform setae, F: filiform setae, B: bacilliform setae.

\begin{tabular}{|c|c|c|c|c|c|c|c|c|c|c|c|c|c|}
\hline \multirow{2}{*}{ Leg } & \multicolumn{2}{|c|}{ Trochanter } & \multicolumn{2}{|c|}{ Basifemur } & \multicolumn{2}{|c|}{ Telofemur } & \multicolumn{2}{|c|}{ Genu } & \multicolumn{2}{|c|}{ Tibia } & \multicolumn{3}{|c|}{ Tarsus } \\
\hline & $\mathrm{S}$ & $\mathrm{F}$ & $S$ & $\mathrm{~F}$ & S & $\mathrm{F}$ & $S$ & $\mathrm{~F}$ & $S$ & $\mathrm{~F}$ & $\mathrm{~S}$ & $\mathrm{~F}$ & B \\
\hline I & $2 / 2$ & $1 / 1$ & $4 / 4$ & $0 / 0$ & $4 / 4$ & $1 / 1$ & $2 / 2$ & $2 / 3$ & $3 / 3$ & $5 / 5$ & $1 / 1$ & $7 / 7$ & $2 / 2$ \\
\hline II & $2 / 2$ & $1 / 1$ & $4 / 4$ & $0 / 0$ & $4 / 4$ & $1 / 1$ & $2 / 2$ & $1 / 3$ & $4 / 4$ & $4 / 4$ & $1 / 1$ & $8 / 7$ & $2 / 2$ \\
\hline III & $2 / 2$ & $1 / 1$ & $4 / 4$ & $0 / 0$ & $4 / 4$ & $1 / 1$ & $4 / 4$ & $1 / 1$ & $5 / 5$ & $4 / 5$ & $1 / 1$ & $8 / 7$ & $2 / 2$ \\
\hline IV & $2 / 2$ & $1 / 1$ & $4 / 4$ & $0 / 0$ & $4 / 4$ & $1 / 1$ & $6 / 6$ & $2 / 2$ & $6 / 6$ & $3 / 4$ & $2 / 2$ & $4 / 4$ & $2 / 2$ \\
\hline
\end{tabular}

Table 3. Length of segments of right and left legs of male (holotype), right/left.

\begin{tabular}{ccccccc}
\hline Leg & Trochanter & Basifemur & Telofemur & Genu & Tibia & Tarsus \\
\hline I & $35 / 38$ & $28 / 33$ & $38 / 38$ & $45 / 45$ & $63 / 63$ & $88 / 93$ \\
II & $35 / 38$ & $28 / 30$ & $40 / 43$ & $48 / 48$ & $70 / 69$ & $93 / 95$ \\
III & $38 / 42$ & $30 / 33$ & $43 / 43$ & $50 / 53$ & $75 / 75$ & $96 / 103$ \\
IV & $60 / 63$ & $45 / 43$ & $50 / 53$ & $78 / 83$ & $93 / 93$ & $108 / 115$ \\
\hline
\end{tabular}




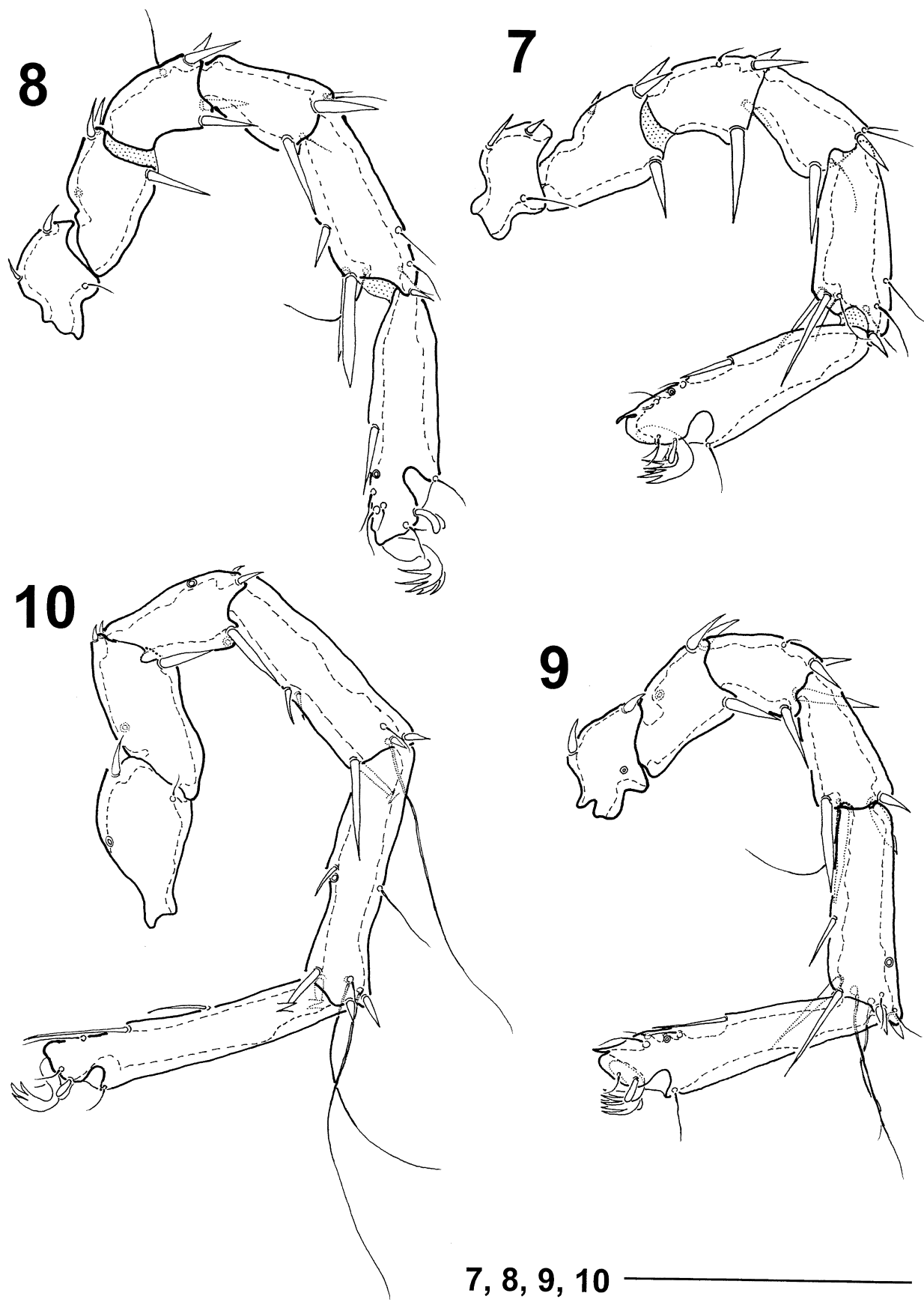

Figs. 7-10. Litarachna sagamiensis sp. nov., male holotype. 7, left Leg-I, lateral view; 8, left Leg-II, lateral view; 9, left Leg-III, lateral view; 10, left Leg-IV, lateral view. Scale $=100 \mu \mathrm{m}(7-10)$.

\section{Systematics}

Family Pontarachnidae Koenike 1910

Genus Litarachna Walter 1925

Litarachna sagamiensis sp. nov. (Japanese name: Sagami-Wadatsumidani)

(Figs. 1-10)

Type series. Holotype: ${ }^{\Uparrow}$, on Sargussum sp. in intertidal zone, Zushi City (N 35 $17^{\prime} 34^{\prime \prime}$, E $\left.139^{\circ} 33^{\prime} 56^{\prime \prime}\right)$, Kanagawa Pref., Japan, 19 July 2012, A. Moto coll. Allotype: 우, same data as holotype. Paratypes: 2 +, 1 nymph, same data as holotype; 3 गे, 1 ㅇ, on Sargussum sp. in intertidal zone,

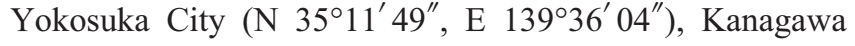
Pref., Japan, 5 February 2012, A. Moto coll.

Etymology. The specific epithet is derived from the type locality "Sagami Bay" (adj. nom., sagamiensis).

Diagnosis. Right and left Cx-I separated from each 
other; ventral tubercles on P-2 absent; ventral tubercle on P4 present; Vgl separated from Vpl-1; Vgl and Vpl-1 located posteriorly to PLA; PMA long and slender; $\mathrm{W}-1$ to $\mathrm{W}-3$ present in female; 49 perigenital setae present in male.

Description. Male (Holotype, NSMT-Ac 13730). Idiosoma 315 long and 250 wide, soft and oval.

Venter (Fig. 1): CX-I to CX-IV fused into a single coxal plate; right and left plates 145 long and 120 wide. Coxal plate furnished with numerous small canals. Right and left $\mathrm{Cx}-\mathrm{I}$ separated. Suture line between $\mathrm{Cx}-\mathrm{I}$ and $\mathrm{Cx}-\mathrm{II}$ complete; suture line between $\mathrm{Cx}-\mathrm{II}$ and $\mathrm{Cx}-\mathrm{III}$, and the line between $\mathrm{Cx}-\mathrm{III}$ and $\mathrm{Cx}-\mathrm{IV}$ incomplete. Cx-I with five setae; $\mathrm{CX}$-II with three setae; $\mathrm{CX}$-III with three setae; $\mathrm{Cx}$-IV with five setae. PMA 58 long, slender, and reaching posterior margin of genital field. PLA 15 long and stocky. Genital field 33 long and 28 wide, situated on membranous cuticle between left and right PMA at level posteriorly to Cx-IV. Sclerotized ring with four pairs of genital setae. Twentyfour and 25 perigenital setae located on right and left side of genital field, respectively. $\mathrm{Vgl}$ and Vpl-1 located posteriorly to PLA and separated from each other. Lyrifissure located posteriorly to Vgl. W-1 and W-4 absent. W-2 located lateroposteriorly to PMA. W-3 located close to posterior margin of idiosoma. Vpl-2 and Vst-2 fused with each other, located lateroposteriorly to W-2. Vst-1 located medioposteriorly to W-2. Vst-3 and Vpl-3 located lateroanteriorly to excretory pore. Excretory pore located close to terminal end of idiosoma.

Dorsum (Fig. 2): A pair of eyes placed in anterior portion. Apl-1 lacking a gland, placed close to anterior margin of idiosoma. Ost-1 and Ost-2 close to each other, located lateroposteriorly to Apl-1. Lpl-1 placed lateroposteriorly to Ost-2. Ost-3 and Apl-2 close to each other, placed medioposteriorly to Lpl-1. Lpl-2 and Lpl-3 placed on lateral portion of dorsum. Dpl-1, Dpl-3, and Dpl-4 placed lateroposteriorly to Apl-2, located on posterior half of dorsum. Dpl-2 placed lateroposteriorly to Dpl-1.

Chelicera (Fig. 3): Typically claw-like in form, consisting of two segments. Basal segment 115 long; claw segment 33-35 long.

Palpi (Fig. 4): P-1 with a spiniform seta on dorsodistal margin; P-2 with a pair of spiniform setae on dorsomedial and dorsodistal margins, respectively; P-2 without a tubercle on ventromedial margin; P-3 with a filiform seta on dorsodistal margin; P-4 with a filiform seta on the dorsodistal margin and a tubercle bearing a pair of filiform setae on ventromedial margin; P-4 without a peg-like seta on ventromedial margin. Proximal and distal heights of P-4 23 and 18, respectively. Length of segments of right and left palpi shown in Table 1.

Legs (Figs. 7-10): Chaetotaxy of right and left legs shown in Table 2. Length of segments of right and left legs given in Table 3.

Female (Allotype, NSMT-Ac 13736). Idiosoma 345 long and 260 wide, soft and oval.

Venter (Fig. 5): Cx-I to CX-IV fused into a single coxal plate; right plate 150 long and 125 wide, left plate 148 long and 115 wide. Coxal plate furnished with numerous small canals. Right and left Cx-I separated. Suture line between $\mathrm{Cx}-\mathrm{I}$ and $\mathrm{Cx}-\mathrm{II}$ complete; suture line between $\mathrm{Cx}-\mathrm{II}$ and $\mathrm{Cx}-$ III, and the line between Cx-III and Cx-IV incomplete. Right Cx-I with two setae; left Cx-I with four setae; Cx-II with two setae; $\mathrm{Cx}$-III with two setae; $\mathrm{Cx}-\mathrm{IV}$ with five setae. PMA 63 long, slender and elongating beyond genital field. Right PLA 10 long; left PLA 20 long and stocky. Genital field 62 long and 45 wide, situated on membranous cuticle between right PMA and left PMA at level posteriorly to suture line between $\mathrm{Cx}-\mathrm{I}$ and $\mathrm{Cx}$-II. Each genital screlite strongly bowed and separated; pregenital screlite 45 long, postgenital 40 long. Vgl and Vpl-1 located posteriorly to PLA and separated from each other. Lyrifissure located posteriorly to Vgl. W-1 located medioposteriorly to PMA. $\mathrm{W}-2$ located lateroposteriorly to W-1. W-3 located close to posterior margin of idiosoma. W-4 absent. Vpl-2 and Vst-2 fused with each other, located lateroanteriorly to W-2. Vst-1 located medioposteriorly to W-2. Vst-3 and Vpl-3 located lateroanteriorly to excretory pore. Excretory pore located close to terminal end of idiosoma.

Table 4. Length of segments of right and left palpi of female (allotype).

\begin{tabular}{cccccc}
\hline Palp & P-1 & P-2 & P-3 & P-4 & P-5 \\
\hline Right & 15 & 73 & 23 & 80 & 30 \\
Left & 15 & 72 & 23 & 80 & 29 \\
\hline
\end{tabular}

Table 5. Chaetotaxy of right and left legs of female (allotype), right/left; S: spiniform setae, F: filiform setae, B: bacilliform setae.

\begin{tabular}{|c|c|c|c|c|c|c|c|c|c|c|c|c|c|}
\hline \multirow{2}{*}{ Leg } & \multicolumn{2}{|c|}{ Trochanter } & \multicolumn{2}{|c|}{ Basifemur } & \multicolumn{2}{|c|}{ Telofemur } & \multicolumn{2}{|c|}{ Genu } & \multicolumn{2}{|c|}{ Tibia } & \multicolumn{3}{|c|}{ Tarsus } \\
\hline & $\mathrm{S}$ & $\mathrm{F}$ & $\mathrm{S}$ & $\mathrm{F}$ & $\mathrm{S}$ & $\mathrm{F}$ & $\mathrm{S}$ & $\mathrm{F}$ & $\mathrm{S}$ & $\mathrm{F}$ & $\mathrm{S}$ & $\mathrm{F}$ & B \\
\hline I & $2 / 2$ & $1 / 1$ & $4 / 4$ & $0 / 0$ & $4 / 4$ & $1 / 1$ & $2 / 2$ & $3 / 3$ & $3 / 3$ & $5 / 5$ & $1 / 1$ & $7 / 7$ & $2 / 2$ \\
\hline II & $2 / 2$ & $1 / 1$ & $4 / 4$ & $0 / 0$ & $4 / 4$ & $1 / 1$ & $2 / 2$ & $3 / 3$ & $4 / 4$ & $4 / 4$ & $0 / 1$ & $7 / 7$ & $2 / 2$ \\
\hline III & $2 / 2$ & $1 / 1$ & $4 / 4$ & $0 / 0$ & $4 / 4$ & $1 / 1$ & $4 / 4$ & $1 / 1$ & $5 / 5$ & $5 / 4$ & $1 / 1$ & $7 / 7$ & $2 / 2$ \\
\hline IV & $2 / 2$ & $1 / 1$ & $4 / 4$ & $0 / 0$ & $4 / 4$ & $1 / 1$ & $6 / 6$ & $2 / 2$ & $6 / 6$ & $3 / 3$ & $2 / 2$ & $3 / 3$ & $2 / 2$ \\
\hline
\end{tabular}

Table 6. Length of segments of right and left legs of female (allotype), right/left.

\begin{tabular}{ccccccc}
\hline Leg & Trochanter & Basifemur & Telofemur & Genu & Tibia & Tarsus \\
\hline I & $38 / 40$ & $30 / 35$ & $45 / 40$ & $49 / 48$ & $65 / 65$ & $93 / 93$ \\
II & $31 / 33$ & $28 / 28$ & $43 / 43$ & $48 / 50$ & $68 / 65$ & $93 / 95$ \\
III & $38 / 38$ & $28 / 30$ & $43 / 40$ & $50 / 53$ & $78 / 75$ & $88 / 103$ \\
IV & $63 / 63$ & $43 / 45$ & $48 / 53$ & $75 / 83$ & $88 / 98$ & $98 / 105$ \\
\hline
\end{tabular}


Dorsum: Same as in male.

Chelicera: Form same as in male. Basal segment 118120 long; claw segment 28 long.

Palpi: Form and chaetotaxy same as in male. Proximal and distal heights of P-4 23 and 18, respectively. Length of segments of right and left palpi shown in Table 4.

Legs: Chaetotaxy of right and left legs given in Table 5. Length of segments of right and left legs given in Table 6.

Nymph (Paratype, NSMT-Ac 13737). Idiosoma 265 long and 190 wide.

Venter (Fig. 6): Cx-I to Cx-IV fused into a single coxal plate; right plate 95 long and 80 wide, left plate 98 long and 83 wide. Coxal plate furnished with numerous small canals. Right and left $\mathrm{Cx}$-I separated. Suture line between $\mathrm{Cx}-\mathrm{I}$ and $\mathrm{Cx}$-II complete; suture line between $\mathrm{Cx}-\mathrm{II}$ and $\mathrm{Cx}-\mathrm{III}$, and the line between $\mathrm{Cx}$-III and Cx-IV incomplete. Cx-I with three setae; $\mathrm{Cx}$-II with two setae; $\mathrm{Cx}$-III with two setae; $\mathrm{Cx}$ IV with three setae. PMA slender and 23 long. PLA stocky and 15 long. Genital field undeveloped. Vgl and Vpl-1 located posteriorly to PLA and separated from each other. Lyrifissure located posteriorly to Vgl. W-1 and W-4 absent. W-2 located lateroposteriorly to genital field. W-3 located close to posterior margin of idiosoma. Vst-1 absent. Vpl-2 and Vst-2 fused with each other, located lateroposteriorly to W-2. Vst-3 and Vpl-3 located lateroanteriorly to excretory pore. Excretory pore located close to terminal end of idiosoma.

Dorsum: Same as in male.

Chelicera: Broken.

Palpi: Form same as in male and female. P-1 with a spiniform seta on dorsodistal margin; P-2 with a spiniform seta on dorsomedial and dorsodistal margins, respectively; P-2 without a tubercle on ventral margin; P-4 with a filiform seta on the dorsodistal margin and a tubercle bearing a pair of filiform setae on ventromedial margin; P-4 without a peglike seta on ventromedial margin. Proximal and distal heights of P-4 15 and 13, respectively. Length of segments of right and left palp shown in Table 7.

Legs: Chaetotaxy of right and left legs shown in Table 8. Length of segments of right and left legs given in Table 9.

Morphological variation and abnormality. The number of setae on coxal plates differs among specimens and even between sides of one specimen. The number of setae on $\mathrm{Cx}$ I-IV varies as follows (right/left). Cx-I: $3-5 / 4,5$ in the male $(n=4), 3,4 / 2,3$ in the female $(n=3)$, and $3 / 3$ in the nymph $(\mathrm{n}=1)$; Cx-II: $2,3 / 2,3$ in the male $(\mathrm{n}=4)$, and $2 / 2$ in the female $(n=3)$ and nymph $(n=1)$; Cx-III: $3,4 / 3$ in the male, $2 / 2$ in the female and nymph; Cx-IV: $5,6 / 5^{-7}$ in the male $(n=4), 5,6 / 5,6$ in the female $(n=3)$, and $3 / 3$ in the nymph $(\mathrm{n}=1)$.

The idiosoma is $315-405$ long and $250-325$ wide in the male $(n=4), 315^{-3} 35$ long and 260-310 wide in the female $(\mathrm{n}=3)$, and 265 long and 190 wide in the nymph $(\mathrm{n}=1)$. The coxal plate is $143^{-150}$ long and $120^{-125}$ wide in the male $(\mathrm{n}=4), 130^{-153}$ long and $113^{-128}$ wide in the female $(\mathrm{n}=3)$, and 95-98 long and 80-83 wide in the nymph $(n=1)$. The length of PMA is $53-63$ in the male $(n=4)$, $60-65$ in the female $(n=3)$, and 23 in the nymph $(n=1)$. The length of PLA is $10^{-18}$ in the male $(n=4), 10^{-20}$ in the female $(\mathrm{n}=3)$, and 15 in the nymph $(\mathrm{n}=1)$. The genital field is $33-40$ long and $28-30$ wide in the male $(n=4)$, and 58-63 long and 40-45 wide in the female $(n=3)$. The widths of pregenital and postgenital sclerites $(n=3)$ are $43^{-}$ 45 and $40^{-45}$, respectively. The number of perigenital setae $(n=4)$ is $49^{-71 .}$.

The lengths of segments of chelicerae are as follows:

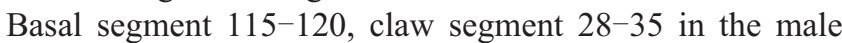

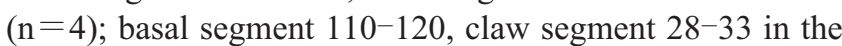
female $(n=3)$.

The lengths of segments of palpi are as follows: P-1 1319; P-2 65-73; P-3 23-28; P-4 73-80; P-5 25-28 in the male $(\mathrm{n}=4)$; P-1 13-20; P-2 68-73; P-3 23-25; P-4 75-80; P-5 28-30 in the female $(\mathrm{n}=3)$; P-1 8-10; P-2 45-48; P-3 18-20; P-4 53-54; P-5 21 in the nymph $(\mathrm{n}=1)$. The proximal height of P-4 is $20^{-23}$ in the male $(n=4), 23$ in the female $(n=3)$, and 15 in the nymph $(n=1)$. The distal height of P-4 is $15^{-18}$ in the male $(n=4), 18^{-20}$ in the female $(\mathrm{n}=3)$, and 13 in the nymph $(\mathrm{n}=1)$.

Table 7. Length of segments of right and left palpi of nymph (paratype).

\begin{tabular}{crcccc}
\hline Palp & P-1 & P-2 & P-3 & P-4 & P-5 \\
\hline Right & 8 & 45 & 20 & 53 & 21 \\
Left & 10 & 48 & 18 & 54 & 21 \\
\hline
\end{tabular}

Table 8. Chaetotaxy of right and left legs of nymph (paratype), right/left; S: spiniform setae, F: filiform setae, B: bacilliform setae.

\begin{tabular}{|c|c|c|c|c|c|c|c|c|c|c|c|c|c|}
\hline \multirow{2}{*}{ Leg } & \multicolumn{2}{|c|}{ Trochanter } & \multicolumn{2}{|c|}{ Basifemur } & \multicolumn{2}{|c|}{ Telofemur } & \multicolumn{2}{|c|}{ Genu } & \multicolumn{2}{|c|}{ Tibia } & \multicolumn{3}{|c|}{ Tarsus } \\
\hline & $\mathrm{S}$ & $\mathrm{F}$ & $\mathrm{S}$ & $\mathrm{F}$ & $\mathrm{S}$ & $\mathrm{F}$ & $\mathrm{S}$ & $\mathrm{F}$ & $\mathrm{S}$ & $\mathrm{F}$ & $\mathrm{S}$ & $\mathrm{F}$ & B \\
\hline I & $1 / 1$ & $1 / 1$ & $3 / 2$ & $0 / 0$ & $4 / 4$ & $1 / 1$ & $2 / 2$ & $1 / 1$ & $3 / 3$ & $5 / 5$ & $1 / 1$ & $6 / 6$ & $2 / 2$ \\
\hline II & $1 / 1$ & $1 / 1$ & $2 / 2$ & $0 / 0$ & $4 / 4$ & $1 / 1$ & $2 / 2$ & $1 / 1$ & $4 / 4$ & $4 / 4$ & $1 / 1$ & $5 / 5$ & $2 / 2$ \\
\hline III & $2 / 1$ & $1 / 1$ & $3 / 2$ & $0 / 0$ & $4 / 4$ & $1 / 1$ & $4 / 4$ & $1 / 0$ & $5 / 5$ & $4 / 4$ & $1 / 1$ & $5 / 6$ & $2 / 2$ \\
\hline IV & $1 / 1$ & $1 / 1$ & $2 / 3$ & $0 / 0$ & $4 / 4$ & $1 / 1$ & $6 / 6$ & $2 / 2$ & $6 / 6$ & $3 / 3$ & $2 / 2$ & $4 / 4$ & $2 / 2$ \\
\hline
\end{tabular}

Table 9. Length of segments of right and left legs of nymph (paratype), right/left.

\begin{tabular}{ccccccc}
\hline Leg & Trochanter & Basifemur & Telofemur & Genu & Tibia & Tarsus \\
\hline I & $25 / 25$ & $20 / 18$ & $25 / 25$ & $30 / 28$ & $43 / 40$ & $63 / 58$ \\
II & $24 / 27$ & $20 / 20$ & $25 / 25$ & $33 / 31$ & $43 / 45$ & $64 / 65$ \\
III & $25 / 28$ & $18 / 20$ & $25 / 25$ & $35 / 33$ & $48 / 50$ & $68 / 65$ \\
IV & $43 / 43$ & $28 / 28$ & $33 / 33$ & $53 / 53$ & $65 / 65$ & $75 / 73$ \\
\hline
\end{tabular}


The chaetotaxy of spiniform and filiform setae of Leg-I, II, III, IV varies as follows (spiniform/filiform). Male $(\mathrm{n}=4)$ : Trochanters: $\quad(1,2 / 1), \quad(1,2 / 1), \quad(1,2 / 1), \quad(2 / 1)$; basifemora: $(4 / 0),(4 / 0),(4 / 0),(3,4 / 0)$; telofemora: $(3,4 / 1)$, (4/1), (4/1), (4/1); genua: $(2 / 2,3),(2 / 1-3),(4 / 1),(6 / 1-3)$; tibiae: $(3 / 5),(4 / 2-5),(5 / 4,5),(6 / 3,4)$; tarsi: $(1 / 7,8),(1 / 7,8)$, $(1 / 7,8), \quad(2 / 4,5)$. Female $(n=3)$ : Trochanters: $(1,2 / 1)$, $(1,2 / 1),(2 / 1),(2 / 1)$; basifemora: $(4 / 0),(4 / 0),(4 / 0),(4 / 0)$; telofemora: (4/1), (4/1), (4/1), (4/1); genua: $(2 / 3),(2 / 3)$, (4/1), (6/3); tibiae: $(3 / 5),(4 / 4),(5 / 4,5),(6 / 3)$; tarsi: $(1 / 7,8)$, $(0,1 / 7),(1 / 7,8),(2 / 3,4)$. Nymph $(\mathrm{n}=1)$ : Trochanters: $(1 / 1)$, $(1 / 1),(1,2 / 1),(1 / 1)$; basifemora: $(2,3 / 0),(2 / 0),(2,3 / 0)$, $(2,3 / 0)$; telofemora: $(4 / 1),(4 / 1),(4 / 1),(4 / 1)$; genua: $(2 / 1)$, $(2 / 1),(4 / 0,1),(6 / 2)$; tibiae: $(3 / 5),(4 / 4),(5 / 4),(6 / 3)$; tarsi: $(1 / 6),(1 / 5),(1 / 5,6),(2 / 4)$.

Several abnormalities are found in paratype specimens. The length of tarsus of Leg-I is quite different between left and right legs of the paratype male (NSMT-Ac 13732). The tarsus of right Leg-I is 95 long, while the tarsus of left Leg-I is 73 long. The number of genital setae is different between the right and left side of the sclerotized ring of the paratype male (NSMT-Ac 13732). Four pairs of genital setae are placed on the right side, while three pairs are on left side of the sclerotized ring. A bipectinate seta instead of a normal filiform seta is exceptionally found on the trochanter of the left Leg-I and II in the paratype female (NSMT-Ac 13735) and the left leg Leg-IV in the paratype male (NSMT-Ac 13732).

Remarks. Litarachna sagamiensis sp. nov. is similar to L. duboscqi from the Mediterranean (Walter 1925), L. hongkongensis from the South China Sea (Smit 2002), and L. marshalli from the Indian Ocean (Wiles et al. 2002) in that the right and left first coxal plates are separated from each other, the ventral tubercle is absent on the second segment of palp and the ventral tubercle is present on the fourth segment of palp. However, the present new species is different from these three congeners in the following characteristics. The ventral glandularium of the present new species is separated from the platelet, while the glandularium of $L$. duboscqi is fused with the first ventral platelet. The ventral glandularium and ventral platelet in the present new species are located posteriorly to posterolateral apodeme, while the glandularium and the platelet of $L$. duboscqi and $L$. hongkongensis are placed between posteromedial and posterolateral apodemes. The three pairs of wheel-like acetabula are present in the female of the new species, while only two pairs are present in L. hongkongensis. The distal margin of medioposterior apodeme in the male is slender in the new species, while the margin is swelling like a hammer in L. marshalli. Furthermore, the male of L. sagamiensis $\mathrm{sp}$ nov. has 49-71 perigenital setae, while $L$. duboscqi and $L$. hongkongensis have about 20 setae and $L$. marsalli has only 6 setae.

\section{Acknowledgements}

We are deeply grateful to Dr. Ronald Vonk, Dr. Herman de Jong,
Dr. Harry Smit and Dr. Ben Brugge (Netherlands Centre for Biodiversity Naturalis) for giving us an opportunity to examine the holotype of Litarachna hongkongensis. Thanks are also due to $\mathrm{Mr}$. Yusuke Miyamoto and Mr. Takahiro Yamada (Nihon University) for their kind help in collecting the present material from Sagami Bay.

\section{References}

Abé, H. 2005. Annotated checklist of Japanese water mites (Acari: Prostigmata: Hydracarina). Acta Arachnol., 54: 111-145.

Cook, D. R. 1986. Water mites from Australia. Mem. Amer. Ent. Inst., 40: $1-568$.

Cook, D. R. 1996. A freshwater species of Pontarachna, (Acari, Pontarachnidae) from South Africa, with a discussion of genital acetabula in the family. Anales Inst. Biol. Univ. Nac. Autón. Méx ico, Ser. Zool., 67: 259-264.

Honma, Y. \& Kitami, T. 1978. Fauna and flora in the waters adjacent to the Sado Marine Biological Station, Niigata University. Annu. Rep. Sado Mar. Biol. St. Niigata Univ., 8: 7-81.

Imamura, T. 1965. A case of water mites, 4. Collection and Experimental Techniques. P. 34. In: Sasa, M. (ed.) Mites, An Introduction to Classification, Bionomics and Control of Acarina. Univ. of Tokyo Press, Tokyo, 486 pp. (In Japanese)

Koenike, F. 1910. Ein Acarinen - insbesondere HydracarinenSystem nebst hydracarinologischen Berichtigungen. Abh. Naturw. Ver. Bremen, 20: 121-164.

Lohmann, H. 1909. Marine Hydrachnidae und Halacaridae. pp. 151154. In: Michaelsen, W. \& Hartmeyer, R. (eds.), Die Fauna Südwest-Australiens, Vol. 2, No.11, Gustav Fischer, Jena.

Pešić, V., Chatterjee, T., Chan, B. K. K. \& Ingole B. 2008. Marine water mites (Acari: Hydrachnidia: Pontarachnidae) from Taiwan, Korea and India, with the first description of the male of Pontarachna australis Smit, 2003. Syst. Appl. Acarol., 13: 70-74.

Pešić, V., Chatterjee, T., Ingole, B., Velip, D. \& Pavićević, A. 2012. A new species of Litarachna Walter, 1925 (Acari: Hydrachnidia) from the West Indian Coast, with a discussion on the diversity of the family Pontarachnidae Koenike, 1910. Cah. Biol. Mar., 53: 547-553.

Pešić, V., Chatterjee, T., Marshall, D. J. \& Pavićević, A. 2011. New records of water mites (Acari: Hydrachna) from Brunei Darussalam, Borneo, with descriptions of two species. Zootaxa, 3018: $50-58$

Pešić, V. \& Smit, H. 2009. New records of water mites (Acari: Hydrachnidia) from Tasmania, with descriptions of three new species. Zootaxa, 2070: 53-62.

Philippi, A. 1840. Zoologische Bemerkungen. Arch. F. Naturgesch., 6: 181-195.

Smit, H. 2002. Two new species of the water mite family Pontarachnidae (Acari: Hydrachnidia), with a discussion of the taxonomic status of Pontarachna hinumaensis Imamura. Zootaxa, 22: $1-8$.

Smit, H. 2003. Five new species of the water mite family Pontarachnidae from Western Australia (Acari: Hydrachnidia). Pp. 547-562. In: Wells, F. E., Walker, D. I. \& Jones, D. S. (eds.) The Marine Flora and Fauna of Dampier, Western Australia. West. Aust. Mus., Perth, 587 pp.

Smit, H. 2008. Two new species of the water mite family Pontarachnidae Koenike from Malaysia (Acari: Hydrachnidia) Entomol. Mitt. Zool. Mus. Hamburg, 15: 29-34.

Smit, H. 2009. Water mites of the family Pontarachnidae from Singapole, with a desceiption of one new species (Acari: Hydrachnidia). Raffles Bull. Zool., Suppl., 22: 203-205.

Tuzovskij, P. V. 1987. Morphology and postembryonic development of water mites. Nauka, Moscow, 172 pp. (In Russian)

Uchida, T. 1935. Marine water mites from Japan. J. Fac. Sci., Hokkaido Imp. Univ., Ser. VI, Zool., 4: 183-195.

Viets, K. O. 1984. A new species of Litarachna (Pontarachnidae, Hydrachnellae, Acari) from the coast of the Philippines. Zool. Anz., 
212: $350-352$.

Walter, C. 1925. Marine Hygrobatidae. Revision der WassermilbenGenera Pontarachna Philippi und Nautarachna Moniez. Int. Rev. Ges. Hydrobiol. Hydrogr., 14: 1-54

Wiles, P. R., Chatterjee, T. \& Troch, M. D. 2002. Two new and one known marine water mite (Acari: Hydrachnidia: Pontarachnidae) from South-East Africa. J. Nat. Hist., 36: 1987-1994.

Womersley, H. 1937. A new species of marine Hydrachnellae from South Australia. Trans. Roy. Soc. S. Aust., 61: 173-174.

Received April 1, 2013 / Accepted May 8, 2013 